\section{Fome, desemprego, corrupção e mortes evitáveis: faces da necropolítica}

Ana Maria Costa1,2, Maria Lucia Frizon Rizzotto $\mathbf{1 , 3}$, Lenaura de Vasconcelos Costa Lobato $\mathbf{1 , 4}^{\mathbf{1}}$
DOI: $10.1590 / 0103-1104202113000$

O POVO BRASILEIRO PADECE DAS AGRURAS ORIUNDAS DA ADOÇÃO DE POLÍTICAS econômicas praticadas pelo governo, que se submete aos interesses do mercado e do capital em detrimento das necessidades e demandas da população. As elites nacionais sempre foram favorecidas nos diferentes governos, mas as discretas mudanças voltadas à redução das desigualdades, ocorridas nos governos Lula e Dilma, provocaram reações a ponto de justificar o golpe institucional-midiático de 2016.

Desde o início, a gestão de Michel Temer alinhou-se aos princípios neoliberais e implementou medidas que supostamente salvariam a economia, mas muito amargas para o povo: a reforma trabalhista, que subtraiu direitos dos trabalhadores, e a Emenda Constitucional 95, que congelou por 20 anos os investimentos sociais do governo federal. A insistência por esse caminho, que já vinha sendo desestimulado por instituições multilaterais, aprofundou o desemprego, a fome e as desigualdades sociais, sem provocar nenhum dinamismo na economia nacional.

Esse já era o cenário social e econômico quando a pandemia da Covid-19 se iniciou em fevereiro de 2020, ou seja, a pandemia não deve ser responsabilizada isoladamente pelas convergentes crises sanitária, econômica e política que assolam o País. Bolsonaro assumiu o comando em 2019 alicerçado na concepção de um Estado voltado a favorecer, ampliar e fortalecer o mercado, apoiado na implementação de uma política econômica fundada na redução dos gastos públicos e na privatização das empresas que compõem o patrimônio nacional. Com o desemprego crescente, um Produto Interno Bruto (PIB) inexpressivo e sem projeto para o Brasil, o governo vem claudicando desde seu primeiro ano de gestão, ao mesmo tempo que inunda a opinião pública de fake news, disseminando o ódio e a intolerância, alimentando com discursos e ideias antidemocráticas uma horda de fanáticos apoiadores que clamam pela intervenção militar e pela destruição das instituições da nossa democracia.

A pandemia e as consequências agravadoras das crises deixam marcas dolorosas. $\mathrm{O}$ luto das famílias de quase 600 mil vítimas, o gigantesco desemprego e a fome que atinge grande parcela da população de norte a sul do País geram desesperança e reduzem as perspectivas de futuro. Pesquisa de opinião realizada no final de $2020^{1}$ revelou que $59 \%$ dos domicílios entrevistados estavam em situação de insegurança alimentar e que pelo menos $15 \%$ conviviam com a falta diária e constante de ter o que comer. Essa situação se agravou ao longo de 2021, uma vez que o desemprego aumentou, o auxílio emergencial

\footnotetext{
${ }^{1}$ Centro Brasileiro de Estudos de Saúde (Cebes) - Rio de Janeiro (RJ), Brasil. dotorana@gmail.com

$\mathbf{2}$ Escola Superior de Ciências da Saúde (ESCS)

- Brasília (DF), Brasil.

3 Universidade Estadual do Oeste do Paraná (Unioeste) - Cascavel $(P R)$, Brasil.

4 Universidade Federal Fluminense (UFF) - Niterói (RJ), Brasil.
} 
foi interrompido de janeiro a abril, o valor pago foi reduzido, e a inflação está perto de $8 \%$, sendo a elevação dos preços do grupo dos alimentos os mais representativos. Dados do Instituto Brasileiro de Geografia e Estatística (IBGE) ${ }^{2}$ mostram que o Índice Nacional de Preços ao Consumidor (INPC), indicador oficial de inflação da baixa renda, já subiu $5,9 \%$ de janeiro a setembro de 2021 , em uma das maiores altas para o período nos últimos 20 anos. Uma inflação que penaliza sobremaneira os mais pobres.

A omissão, a incompetência e o negacionismo do governo federal no enfrentamento da pandemia imobilizaram o Ministério da Saúde, que não assumiu o seu papel de coordenador do Sistema Único de Saúde (SUS), não comprou vacinas, testes e insumos em tempo oportuno. Além disso, a falta de planejamento fez com que deixasse vencer a validade de vacinas, medicamentos, testes de diagnóstico, entre outros itens no valor de R $\$ 243$ milhões, os quais serão incinerados ${ }^{3}$.

A Comissão Parlamentar de Inquérito (CPI) instalada no Senado Federal vem exibindo ao Brasil a radiografia grotesca da corrupção no interior do governo, envolvendo militares, gestores, empresários, religiosos e políticos que se locupletaram para enriquecer com a crise sanitária, a dor e a morte dos brasileiros. Todos os dias, vêm à luz novas denúncias que envolvem desde negociatas até a realização de 'estudos' com resultados encomendados para justificar o uso de medicamentos sem eficácia para a Covid-19, de interesse da presidência da República. Brasileiros seguem estarrecidos com a dimensão e a gravidade dos crimes que envolvem o presidente e que embasam e justificam os mais de cem pedidos de impeachment sistematicamente ignorados pelo presidente da Câmara Federal em seu interesse e em obediência às elites endinheiradas que comandam a política nacional e desdenham da pobreza existente no País, como bem observou Noam Chomsky em recente entrevista: "raramente vi um país onde a elite tem tanto desprezo pelos pobres como o Brasil"4.

A necropolítica do governo federal já provocou a morte de quase 600 mil pessoas pela Covid-19, milhares delas evitáveis. Hallal ${ }^{5}$ afirma que de cada cinco mortes ocorridas no Brasil por essa doença, quatro poderiam ter sido evitadas. O cálculo se baseia na mortalidade por milhão de habitantes, sendo que, no mundo, morreram 488 pessoas por cada milhão de habitantes; e no Brasil, 2,3 mil mortes por cada milhão de habitantes, ou seja, quatro vezes mais que a média mundial.

Wernek et al. ${ }^{6}$ consideram mortes evitáveis por Covid-19 aquelas que não ocorreriam se fossem adotadas ações populacionais e ações em serviços de saúde. As ações populacionais se constituem de medidas para redução dos níveis de transmissão da doença com consequente redução do número de casos e mortes, como: fechamento provisório de atividades econômicas, distanciamento físico, redução da mobilidade, limitação de aglomerações, controle de portos, aeroportos e fronteiras. As ações em serviços de saúde compreendem medidas para redução da gravidade da doença e a morte, compreendidas por cuidados ambulatoriais e hospitalares. As medidas para redução da probabilidade de infecção compreendem tanto ações populacionais como ações de serviços de saúde: proteção individual, rastreamento de casos, rastreamento prospectivo e retroativo de contatos, isolamento, quarentena e vacinas.

Certamente, o desrespeito intencional do governo federal à ciência, às recomendações internacionais e às autoridades sanitárias; a ausência de coordenação nacional no enfrentamento da pandemia, a demora na aquisição de vacinas - único medicamento capaz de prevenir mortes por Covid-19 - acumulam-se como responsáveis pelas centenas de milhares de mortes evitáveis ocorridas pela doença no País. 
Passados oito meses após o início da vacinação, em 17 de janeiro de 2021, apenas $35 \%$ da população está completamente vacinada com duas doses do imunizante ou com dose única, e 67,3\% tomaram pelo menos uma dose da vacina ${ }^{7}$. Isso está muito aquém do desejado e da capacidade que o SUS tem de realizar campanhas de vacinação em massa no Brasil. A lentidão da vacinação mantendo a baixa cobertura vacinal facilita a propagação do vírus, a emergência de novas variantes e aumenta ainda mais o número de mortes evitáveis. Embora, neste momento, haja uma clara redução da taxa de contaminação e das mortes por Covid-19, resultante da vacinação, segue preocupante a disseminação da variante Delta em alguns estados. A recomendação da terceira dose ou dose de reforço especialmente aos idosos e a extensão da aplicação das vacinas aos adolescentes e infantes estão no centro de embates e joguetes políticos entre governos federal e estaduais.

Nesse cenário, o País se consolida como um dos países que mais sofreram os impactos da pandemia sem qualquer estratégia para evitar ou proteger a população. Reconstruir o Brasil irá requerer o envolvimento e o trabalho de todos, particularmente das forças democráticas que reconhecem um destino digno ao povo e à nação brasileira.

A pandemia comprovou a importância do SUS, mas ele permanece ameaçado pelas políticas neoliberais e pela sanha dos que querem se servir dele para enriquecer. As necessidades de saúde vão aumentar pelos efeitos deletérios da crise social e econômica, pelo represamento das medidas de saúde durante a pandemia e pelas sequelas ainda desconhecidas decorrentes da Covid-19. Precisaremos de um SUS mais forte, com mais recursos e mais presente na vida da população. Contudo, permanece forte a proposta de que há que se controlar os gastos públicos e reduzir o tamanho do Estado. A população sabe bem o que é controlar gastos e não defende dispêndio, mas, com certeza, defende que tamanho bom de Estado é aquele no qual cabem o bem-estar e os direitos dos cidadãos. É urgente acabar com o teto de gastos, que já se mostrou falido. Para mais recursos, precisamos de uma reforma tributária que proteja o trabalho e a produção e que cobre dos ricos e do capital improdutivo.

Para a comunidade do campo da saúde, fica o desafio de retomar as bases da reforma sanitária em ação política permanente que aprofunde a consciência coletiva com valores da democracia e da importância dos direitos sociais e da saúde.

\section{Colaboradoras}

Costa AM (0000-0002-1931-3969)*, Rizzotto MLF (0000-0003-3152-1362)* e Lobato LVC (0000-0002-2646-9523)* contribuíram igualmente para a elaboração do manuscrito. ${ }^{*}$ Orcid (Open Researcher and Contributor ID).
${ }^{*}$ Orcid (Open Researcher and Contributor ID). 


\section{Referências}

1. Galindo E, Teixeira MA, Araújo M, et al. Efeitos da pandemia na alimentação e na situação da segurança alimentar no Brasil. Berlin: Food for Justice; 2021. [acesso em 2021 set 4]. Disponível em: https://refubium.fu-berlin.de/bitstream/ handle/fub188/29813/WP_\%234_final_version. pdf? sequence $=2$.

2. Fernandes F. IPCA-15: Inflação de alimentos aumentou mais do que o dobro em agosto. Correio Braziliense. 2021 ago 25. [acesso em 2021 set 4]. Disponível em: https://www.correiobraziliense. com.br/economia/2021/08/4945759-ipca-15-inflacao-de-alimentos-aumentou-mais-do-que-o-dobro-em-agosto.html.

3. Carta Capital. Governo Bolsonaro deixa vencer $\mathrm{R} \$$ $243 \mathrm{mi}$ em vacinas, testes e remédios. Carta Capital. 2021 set 6. [acesso em 2021 set 8]. Disponível em: https://www.cartacapital.com.br/cartaexpressa/ governo-bolsonaro-deixa-vencer-r-243-mi-em-vacinas-testes-e-remedios/.

4. Brasil247. "Raramente vi um país onde a elite tem tanto desprezo pelos pobres como o Brasil”, diz
Noam Chomsky. Brasil 247. 2021 ago 30. [acesso em 2021 set 6]. Disponível em: https://www.brasil247. com/ideias/raramente-vi-um-pais-onde-a-elite-tem-tanto-desprezo-pelos-pobres-como-o-brasil-diz-noam-chomsky.

5. BNews. CPI da Covid: Autores de estudo sobre mortes por coronavírus evitáveis depõem nesta quinta-feira. BNews. 2021 jun 24. [acesso em 2021 set 8]. Disponível em: https://www.bnews.com.br/ noticias/politica/312106,cpi-da-covid-autores-de-estudo-sobre-mortes-por-coronavirus-evitaveis-depoem-nesta-quinta-feira.html.

6. Werneck GL, Bahia L, Moreira JPL, et al. Mortes evitáveis por Covid-19 no Brasil. [acesso em 2021 set 6]. Disponível em: https://idec.org.br/sites/default/files/mortes_evitaveis_por_covid-19_no_brasil_para_internet_l.pdf.

7. Our World in Data. Coronavirus (COVID-19) Vaccinations. 2021. [acesso em 2021 set 8]. Disponível em: https://ourworldindata.org/covid -vaccinations?country=BRA. 